\title{
Ice Nucleation Activity of Graphene and Graphene Oxides
}

\author{
Thomas Häusler, ${ }^{\dagger}{ }^{\circ}$ Paul Gebhardt, ${ }^{\dagger}$ Daniel Iglesias, ${ }^{\ddagger \odot}$ Christoph Rameshan, ${ }^{\dagger}$ Silvia Marchesan, ${ }^{\ddagger 0}$ \\ Dominik Eder, ${ }^{\dagger}$ and Hinrich Grothe ${ }^{\dagger, *(0)}$ \\ ${ }^{\dagger}$ Institute of Materials Chemistry, TU Wien, 1060 Vienna, Austria \\ ${ }^{\ddagger}$ Department of Chemical and Pharmaceutical Sciences, Università degli studi di Trieste, 34127 Trieste, Italy
}

\section{Supporting Information}

\begin{abstract}
Aerosols can act as cloud condensation nuclei and/or ice-nucleating particles (INPs), influencing cloud properties. In particular, INPs show a variety of different and complex mechanisms when interacting with water during the freezing process. To gain a fundamental understanding of the heterogeneous freezing mechanisms, studies with proxies for atmospheric INPs must be performed. Graphene and its derivatives offer suitable model systems for soot particles, which are ubiquitous aerosols in the atmosphere. In this work, we present an investigation of the ice nucleation activity (INA) of different types of graphene and graphene oxides. Immersion droplet freezing experiments as well as additional analytical analyses, such as X-ray photoelectron spectroscopy, Raman

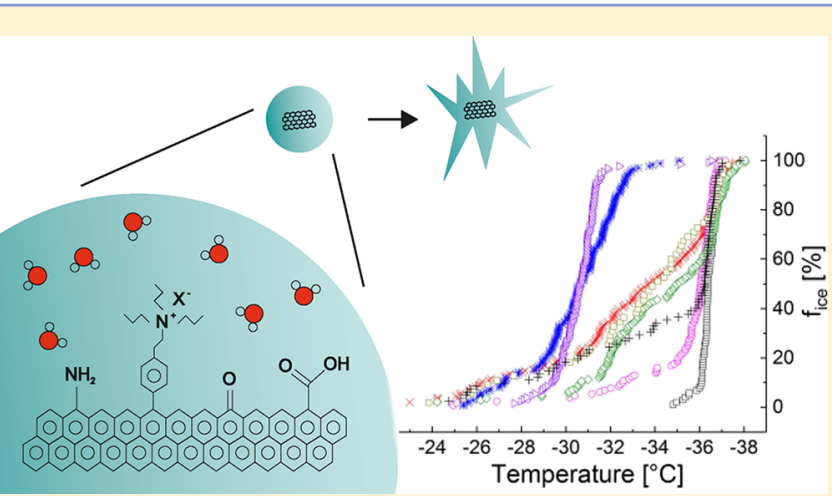
spectroscopy, and transmission electron microscopy, were performed. We show within a group of samples that a highly ordered graphene lattice (Raman G band intensity $>50 \%$ ) can support ice nucleation more effectively than a lowly ordered graphene lattice (Raman G band intensity $<20 \%$ ). Ammonia-functionalized graphene revealed the highest INA of all samples. Atmospheric ammonia is known to play a primary role in the formation of secondary particulate matter, forming ammonium-containing aerosols. The influence of functionalization on interactions between the particle interface and water molecules, as well as on hydrophobicity and agglomeration processes, is discussed.
\end{abstract}

\section{INTRODUCTION}

At temperatures below $-35{ }^{\circ} \mathrm{C}$, ice forms via the homogeneous nucleation of supercooled droplets or heterogeneous nucleation on ice-nucleating particles (INPs). ${ }^{1-3}$ At temperatures above $-35{ }^{\circ} \mathrm{C}$, heterogeneous nucleation is considered to be the dominant mechanism. ${ }^{3,4}$ Therefore, INPs play a major role in the ice forming process in clouds. The composition and origin of INPs have been studied intensively over the past few decades, as summarized, for example, by Murray et al. ${ }^{5}$ However, the microscopic and molecular mechanisms of heterogeneous ice nucleation are complex and remain poorly understood. Necessary attributes, such as the ice-like structure or hydrophobicity of the INP, can rarely be applied. ${ }^{3}$ Factors controlling heterogeneous processes have been investigated intensively, but the knowledge remains fragmentary. ${ }^{5}$ To answer the major question of ice nucleation-what makes an effective ice-nucleating site?-investigations need to focus on simple INP proxies. Consequently, more laboratory and atmospheric data are required.

In this work, we focus on surrogates of soot particles. A series of studies demonstrated that black carbon as well as organic soot components forms a large fraction of urban aerosols. ${ }^{7-9}$ The ice nucleation activity (INA) of soot has been wellinvestigated, for example, by DeMott ${ }^{10}$ and Dymarska et al. ${ }^{11}$ Nevertheless, the complexity of the atmospheric soot makes forecasts of their ice-nucleating behavior rather difficult. Several laboratory and field studies showed that an increase in the INA of aged soot results from an increase in the hydrophilicity of the surface upon oxidation. ${ }^{12-16}$ However, oxidation also impacts the nanostructure of the soot, making it difficult to assess the separate effects of soot nanostructure and hydrophilicity via experiments. Therefore, graphene, a simple proxy substance with chemical and structural similarities to soot, ${ }^{17,18}$ was investigated to confirm or correct the established rules regarding the necessary ice nucleation characteristics. Graphene is a single two-dimensional layer of carbon atoms bound in a hexagonal lattice structure. ${ }^{17}$ It was first isolated and identified in 1962 by Böhm. ${ }^{19}$ Since then, graphene has been the focus of extensive studies, primarily because of its exceptional electrical, thermal, and mechanical properties. ${ }^{20}$

Lupi and Molinero ${ }^{21}$ used molecular dynamics simulations to investigate the effect of changes in the hydrophilicity of model graphitic surfaces on the freezing temperature of ice. Their results indicate that the ordering of liquid water in contact with the surface plays an important role in the heterogeneous ice nucleation mechanism and that the hydrophilicity of the surface

Received: October 28, 2017

Revised: February 23, 2018

Published: March 1, 2018 
is not generally a good predictor of the INA. These ordered water molecule domains of bilayer hexagons are necessary for the INA of graphene but have not been observed on hydrophobic or hydrophilic atomically rough surfaces. They suggested that knowledge of the actual nanostructure and spatial distribution of chemical groups in soot and other atmospheric carbon particles is needed for an accurate prediction of the INA of these aerosols. A molecular dynamics study by $\mathrm{Bi}$ et al. ${ }^{22}$ revealed that a crystalline graphitic lattice with an appropriate hydrophilicity may indeed template ice and thus significantly enhance its INA. Their calculations demonstrated that the templating effect is found to transit from within the first contact layer of water to the second as the hydrophilicity increases, yielding an oscillating distinction in the INA of crystalline and amorphous graphitic surfaces. Furthermore, it was evident that crystalline graphene becomes up to $10^{5}$ times more efficient within certain hydrophilicity ranges, suggesting that the crystallinity is also a key factor for ice nucleation under such hydrophilicity. The experimental investigation of Zheng et $\mathrm{al}^{23}$ showed that a sprinkle of graphene oxide nanoflakes is effective for condensing water nanodroplets and seeding ice epitaxy on graphite under ambient conditions. They discovered that ice nucleation and growth can be influenced by modifying the functional groups of graphene oxide nanoflakes and by intermolecular hydrogen bonding between nanoflakes. Carboxylate groups introduced by base treatment play a key role in the INA of graphene oxide nanoflakes. So-called "charge-assisted hydrogen bonding" 24 allows interaction with water molecules, thus increasing the INA. Reduction via acid or ammonium treatment decreases the INA significantly. Furthermore, by arranging graphene oxide nanoflakes in one dimension, an ice-like structure can be induced, leading to an increase in the INA. A phenyl ring structure, however, reduces the number of possible hydrogenbonding carbonyl sites for ice nucleation and decreases the INA.

Whale et al. ${ }^{25}$ investigated different kinds of carbon nanomaterials in laboratory experiments using an immersion freezing technique. Their results agreed with the calculations done by Lupi and Molinero ${ }^{21}$ and Lupi et al. ${ }^{26}$ and showed that materials with a lower oxidation state nucleate ice more efficiently than materials with a higher oxidation state. Any oxidation, roughness or curvature was found to decrease the observed nucleation temperature. The result that oxidized surfaces nucleate ice less well than atomically flat surfaces is somewhat in contradiction with the commonly stated "chemical bonding" requirement for ice nucleation. ${ }^{3}$ Oxides or other polar groups on the surface of INPs are meant to offer so-called functional sites that are able to interact with water molecules and nucleate ice.

Biggs et al. ${ }^{27}$ modified graphene oxides by means of thiolepoxy chemistry, resulting in materials with increased INA. They revealed that hydrophobic chains increased the heterogeneous nucleation temperature from -22.5 to -12.5 ${ }^{\circ} \mathrm{C}$. Hydrophilic surface modifications did not promote the activity but also did not reduce the underlying INA of the graphene oxide. They suggested that due to the functionalization and increase in hydrophobicity, an increased degree of aggregation occurred, with larger aggregates potentially leading to more nucleation. Ammonia is highly relevant in the atmosphere, as it has been shown to play a primary role in the formation of secondary particulate matter, forming ammonium-containing aerosols. ${ }^{28}$ Ammonium-containing aero- sols constitute the major fraction of $\mathrm{PM}_{2.5}$ aerosols in the atmosphere. ${ }^{28}$ Anthropogenic ammonia originates, for example, from soil because of agriculture activities and from industrial and traffic emissions. ${ }^{29,30}$ Therefore, ammonia-functionalized graphene should be investigated.

Because of the differences in approaches concerning the required features of an INP, investigations of simple and closely related INPs are important to gain more information on the characteristics of a functional site. Therefore, graphene was chosen to be a good proxy substance to fundamentally understand heterogeneous ice nucleation. The goal of our study was to investigate the immersion-mode ice nucleation characteristics of different kinds of graphene and graphene modifications. Moreover, the graphene samples were analyzed regarding their chemistry and structure by means of X-ray photoelectron spectroscopy (XPS), Raman spectroscopy, and transmission electron microscopy. Combining these data, we propose possible explanations as to why some graphene samples are good INPs while others are not.

\section{METHODS}

The INA was determined by an oil-immersion freezing technique, which was used in recent publications, for example, by Hauptmann et al., ${ }^{31}$ Pummer et al., ${ }^{32}$ and Zolles et al. ${ }^{33}$ Supplementary analytical techniques were applied to characterize the chemical properties, surface and bulk properties, and morphology of the INPs.

Cryomicroscopy. The measurement setup consisted of a custom-built freezing cell that was placed directly underneath a light microscope. This experimental setup has been used in previous studies, in which a detailed description can be found. ${ }^{32,33}$ Here, only a short description of the technique is given. The experimental setup consisted of a light microscope to observe the freezing experiment, a freezing cell to cool the sample, and a computer to control the cell temperature and cooling rate. The main part of the custom-built freezing cell is a thermoelectric cooler (TEC, Peltier element Quick-Cool QC31-1.4-3.7). The TEC enables cooling rates between 0.1 and 10 ${ }^{\circ} \mathrm{C} / \mathrm{min}$ down to a temperature of $-40{ }^{\circ} \mathrm{C}$. Two gas connectors on the shell of the freezing cell allow flushing with dry nitrogen. This is done before every experiment to remove humidity and to establish a neutral atmosphere. The freezing process is observed via a glass window on top of the freezing cell using the light microscope. The INA of the graphene samples was determined in the immersion freezing mode using a water-oil emulsion technique. A stable suspension of the INPs in ultrapure water was achieved by sonication for $5 \mathrm{~min}$ with an operating frequency of $40 \mathrm{kHz}$. Graphene is considered to disperse poorly in water. ${ }^{34,35}$ Nevertheless, the oxidation of graphene together with the use of sonication allows graphene and graphene oxides to be dispersed in a larger number of solvents, including water. ${ }^{34,35}$ The samples used in this work revealed a sufficient degree of oxidation to achieve stable suspensions. Images of the selected aqueous graphene and graphene oxide suspensions immediately after sonication and after settling for $30 \mathrm{~min}$ are provided in the Supporting Information (see Figure S1). To avoid any subsequent phase separation, further preparation steps were carried out immediately after sonication. Graphene samples from SigmaAldrich were purchased directly as an aqueous suspension. The suspensions were emulsified into an oil matrix (80 wt \% paraffin, 20 wt \% lanolin), producing droplets in the micrometer range with a diameter of $20-80 \mu \mathrm{m}$. Only droplets 
with diameters between 35 and $45 \mu \mathrm{m}$ were used for evaluation. The water-oil emulsion was put on a glass slide and placed on the TEC. The migration of individual particles into the oil phase cannot be excluded. To minimize migration, the time between emulsification and the start of the cooling process was intentionally kept short. A refreezing experiment was performed to demonstrate that no migration into the oil phase occurs during the freezing experiment and is provided in the Supporting Information (see Figure S2).

The TEC was cooled at a constant cooling rate of $2{ }^{\circ} \mathrm{C} / \mathrm{min}$. The temperature accuracy was $\pm 0.5{ }^{\circ} \mathrm{C}$. The freezing process was recorded with a microscope camera and then analyzed. The frozen droplets can be easily distinguished from the liquid droplets, as they appear darker because of their different lightscattering properties. The so-called ice nucleation active surface site density $n_{s}^{36-39}$ was used to describe ice nucleation because the total surface area of INPs per droplet is important to their activity, as predicted by the classical nucleation theory and confirmed by Edwards et al. ${ }^{40} N_{0}$ is the total number of droplets in the experiment, $N_{\mathrm{F}}$ is the number of frozen droplets at temperature $T$, and $s$ is the particle surface per droplet. The fraction of frozen droplets $f(T)$ is given by

$$
f_{\text {ice }}(T)=\frac{N_{\mathrm{F}}(T)}{N_{0}}=1-\exp \left[-n_{\mathrm{s}}(T) \times s\right]
$$

The surface area was determined via nitrogen adsorption and assumed to be equal to the available surface area in suspension.

By increasing the size of droplets from cloud droplet size (diameters of approximately $10 \mu \mathrm{m}$ ) to approximately $40 \mu \mathrm{m}$, the surface area per droplet for a constant mass fraction of INPs in water was increased. According to eq 1 , this allows the quantification of $n_{\mathrm{s}}$ to smaller values and the determination of nucleation efficiencies over a wider range of temperatures than that is possible by using cloud-sized droplets. ${ }^{41}$

X-ray Photoelectron Spectroscopy. XPS was carried out using the facilities of the Analytical Instrumentation Center AIC at the TU Wien. Measurements were performed with a SPECS XPS spectrometer equipped with an Al K $\alpha$ X-ray source ( $\mu$ Focus 350$)$ and a hemispherical WAL-150 analyzer. The excitation energy was set to $1486.6 \mathrm{eV}$, the pass energy was 30 $\mathrm{eV}$, and the resolution was $50 \mathrm{meV}$. The lower detection limit of quantification was 0.1 at. \% with an accuracy of $10-20 \%$, depending on the element. For preparation, the samples were drop-coated on a silicon single crystal.

Raman Spectroscopy. The Raman microscope system (Jobin Yvon, LabRAM HR) consisted of a light microscope (Olympus BX) coupled to a Raman spectrometer. A 20-fold objective and a grating with $300 \mathrm{~g} / \mathrm{mm}$ were used. Furthermore, 60 scans with an exposure of $5 \mathrm{~s}$ each were collected to obtain a sufficient signal-to-noise ratio using a laser with a wavelength of $633 \mathrm{~nm}$. The interpretation and evaluation of the Raman spectra were performed according to Sadezky et $\mathrm{al}^{42}$ By applying and fitting potential vibrational bands (see Table 1) to the measured Raman spectra, qualitative and quantitative descriptions of the graphene lattice and its disorder can be made. The appearance of individual vibrational bands provides a qualitative description, while the proportional integrated intensities provide information on the contribution of each vibration. The band intensities are expressed as a fraction of the total intensity.

Transmission Electron Microscopy. TEM measurements were performed on FEI Tecnai F20 with an acceleration voltage
Table 1. First-Order Raman Bands and Vibrational Modes of Soot and Graphite According to Sadezky et al. ${ }^{42}$ for Interpretation of the Obtained Raman Spectra (vs = Very Strong, $\mathbf{s}=$ Strong, $\mathbf{m}=$ Medium, and $\mathbf{w}=$ Weak $)^{a}$

\begin{tabular}{|c|c|c|c|}
\hline \multirow[b]{2}{*}{ band } & \multicolumn{2}{|c|}{ Raman shift $\left[\mathrm{cm}^{-1}\right]$} & \multirow[b]{2}{*}{ vibrational mode ${ }^{b}$} \\
\hline & soot & $\begin{array}{l}\text { disordered } \\
\text { graphite }^{c}\end{array}$ & \\
\hline G & $\sim 1580, \mathrm{~s}$ & $\sim 1580, \mathrm{~s}$ & ideal graphitic lattice ( $E_{2 g}$ symmetry) \\
\hline D1 & $\sim 1350$, vs & $\sim 1350, \mathrm{~m}$ & $\begin{array}{l}\text { disordered graphitic lattice (graphene layer } \\
\text { edges, } A_{1 g} \text { symmetry) }\end{array}$ \\
\hline $\mathrm{D} 2$ & $\sim 1620, \mathrm{~s}$ & $\sim 1620, \mathrm{w}$ & $\begin{array}{l}\text { disordered graphitic lattice (surface } \\
\text { graphene layers, } E_{2 g} \text { symmetry) }\end{array}$ \\
\hline D3 & $\sim 1500, \mathrm{~m}$ & & amorphous carbon (Gaussian line shaped) \\
\hline D4 & $\sim 1200, \mathrm{w}$ & & $\begin{array}{l}\text { disordered graphitic lattice }\left(\mathrm{A}_{1 \mathrm{~g}} \text { symmetry }\right) \text {, } \\
\text { polyenes, and ionic impurities }\end{array}$ \\
\hline
\end{tabular}

${ }^{a}$ Minor changes in the Raman shifts may occur because of the different measurement parameters. ${ }^{b}$ Lorentzian line shaped unless otherwise mentioned. ${ }^{c}$ Polycrystalline graphite $(<100 \mathrm{~nm})$ and boron-doped highly oriented polycrystalline graphite (HOPG).

of $200 \mathrm{kV}$. The samples were prepared by adding dropwise an aqueous or ethanolic solution on Lacey(R)-coated copper grids.

Nitrogen Adsorption. The surface areas of the samples were measured using a commercial liquid nitrogen adsorption system (ASAP 2020, Micromeritics). Data evaluation was based on the model by Brunauer, Emmett, and Teller (BET). ${ }^{43}$

Description of Materials. We investigated a variety of functionalized and nonfunctionalized graphene and graphene oxide materials with different chemical and structural characteristics to evaluate the dependence of the INA on the surface chemistry, micromorphology, and nanomorphology. Four graphene oxides (GO) were chosen for investigation: (i) GO synthesized by our group (GO-DE), (ii) GO purchased from Sigma-Aldrich (GO-SA), (iii) ammonia-functionalized GO $\left(\mathrm{GO}-\mathrm{NH}_{2}\right)$, and (iv) nanosized colloidal GO (GO-nano). Moreover, three graphene samples were analyzed: (i) nonfunctionalized graphene (G-non) and (ii) and (iii) covalently functionalized graphene G-NPr ${ }_{3}^{+} \mathrm{X}^{-}(\mathrm{X}=\mathrm{I}$ and $\mathrm{OH})$. Table 2 summarizes the material characteristics, including the source of synthesis and the specific surface area according to BET. The representative chemical structures are given in Figure 1. The synthesis and further characterization are provided in the Supporting Information (see Scheme S1 and S2, Figures S3S16).

\section{RESULTS}

The INA of the entire set of samples is shown in Figure 2. For clarity, the samples were divided into two groups according to their chemical characteristics: (i) graphene, including G-non, G-NPr ${ }_{3}^{+} \mathrm{I}^{-}$, and $\mathrm{G}-\mathrm{NPr}_{3}{ }^{+} \mathrm{OH}^{-}$, and (ii) graphene oxides, including GO-DE, GO-SA, GO-nano, and $\mathrm{GO}-\mathrm{NH}_{2}$ (see Table 2).

Graphene. Covalently functionalized graphene $\left(\mathrm{G}-\mathrm{NPr}_{3}{ }^{+} \mathrm{I}^{-}\right.$ and $\mathrm{G}-\mathrm{NPr}_{3}{ }^{+} \mathrm{OH}^{-}$) show a similar INA with slightly increased $n_{\mathrm{s}}$ values of $\mathrm{G}-\mathrm{NPr}_{3}{ }^{+} \mathrm{OH}^{-}$between -30 and $-36.5{ }^{\circ} \mathrm{C}$ compared to $\mathrm{G}-\mathrm{NPr}_{3}{ }^{+} \mathrm{I}^{-}$. In contrast, nonfunctionalized graphene (G-non) shows an increased INA once the temperature is below $-28{ }^{\circ} \mathrm{C}$ compared to the functionalized samples. XPS measurements were performed to determine the elemental composition and the $\mathrm{sp}^{2}$-hybridized carbon $\left(\mathrm{C}-\mathrm{sp}^{2}\right)$ proportion. The $\mathrm{C}-\mathrm{sp}^{2}$ proportions are representative for the graphitic carbon ratio (see Table 3). The detailed list of XPSdetermined carbon components is given in the Supporting 
Table 2. List of Samples Investigated, Including the Sources of Each Sample, BET-Determined Surface Areas and a Short Description of the Samples, Including TEM-Determined Particle Thickness and Shape

\begin{tabular}{|c|c|c|}
\hline material & $\begin{array}{l}\text { surface } \\
\text { areas } \\
{\left[\mathrm{m}^{2} / \mathrm{g}\right]}\end{array}$ & description \\
\hline \multicolumn{3}{|c|}{ Graphene Oxides } \\
\hline $\mathrm{GO}-\mathrm{DE}^{a}$ & 112 & $\begin{array}{l}\text { large single-layer graphene oxide sheets } \\
(>1 \mu \mathrm{m})\end{array}$ \\
\hline $\mathrm{GO}-\mathrm{SA}^{b}$ & $<10$ & $\begin{array}{l}\text { large } 2-7 \text { multi-layer graphene oxide sheets } \\
(>1 \mu \mathrm{m})\end{array}$ \\
\hline GO- $\mathrm{NH}_{2}{ }^{b}$ & $<10$ & $\begin{array}{l}\text { large } 2-7 \text { multi-layer graphene oxide sheets } \\
(>1 \mu \mathrm{m}) \text {, ammonia functionalized }\end{array}$ \\
\hline GO-nano ${ }^{b}$ & 176 & $\begin{array}{l}\text { graphene oxide nanocolloids with varying } \\
\text { particle size/shape up to } 200 \mathrm{~nm} \text { and } \\
\text { thickness of }>3 \mathrm{~nm}\end{array}$ \\
\hline \multicolumn{3}{|l|}{ Graphene } \\
\hline G-non ${ }^{a}$ & $<10$ & $\begin{array}{l}\text { nonfunctionalized graphene flakes with a } \\
\text { diameter of } 400 \mathrm{~nm} \text { and up to } 7 \text { layers; } \\
\text { precursor for } \mathrm{G}-\mathrm{NPr}_{3}{ }^{+} \mathrm{I} / \mathrm{OH}^{-}\end{array}$ \\
\hline G-NPr ${ }_{3}^{+} \mathrm{I}^{-a}$ & $<10$ & $\begin{array}{l}\text { covalently functionalized graphene with } \mathrm{I}^{-} \text {as } \\
\text { the counter ion; same form and shape as that } \\
\text { of G-non }\end{array}$ \\
\hline $\mathrm{G}-\mathrm{NPr}_{3}{ }^{+} \mathrm{OH}^{-a}$ & $<10$ & $\begin{array}{l}\text { covalently functionalized graphene with } \mathrm{OH}^{-} \text {as } \\
\text { the counter ion; same form and shape as that } \\
\text { of G-non }\end{array}$ \\
\hline
\end{tabular}

${ }^{a}$ Synthesized by our workgroup. ${ }^{b}$ Acquired from Sigma-Aldrich Chemistry.
Information (see Table S1). The composition of the three samples is similar and consists of approximately 91-92 at. \% carbon and 4-9 at. \% oxygen. G-NPr ${ }_{3}^{+} \mathrm{I}^{-}$and $\mathrm{G}-\mathrm{NPr}_{3}{ }^{+} \mathrm{OH}^{-}$ show a nitrogen proportion of $3-4$ at. $\%$ as well as 1 at. \% iodine for $\mathrm{G}-\mathrm{NPr}_{3}{ }^{+} \mathrm{I}^{-}$originating from the functionalization (see Figure 1). The C-sp ${ }^{2}$ proportions are between 72 at. \% for $\mathrm{G}-\mathrm{NPr}_{3}{ }^{+} \mathrm{OH}^{-}$and 91 at. \% for $\mathrm{G}-\mathrm{NPr}_{3}{ }^{+} \mathrm{I}^{-}$.

Raman spectroscopy was performed and analyzed according to Sadezky et al. ${ }^{42}$ to distinguish the differences in the microstructure, lattice disorder, and short-range order. The Raman spectra (see Table 4 and Figure 3) reveal that nonfunctionalized graphene (G-non) has fewer structural defects, shown by the lower intensity of the disordered band D1 (layer edge disorder) of $27 \%$ and the higher intensity of the ideal graphite band $\mathrm{G}$ of $69 \%$ compared to those of covalently functionalized graphene. Covalently functionalized graphene exhibits an integrated intensity of D1 of up to $40 \%$ for G$\mathrm{NPr}_{3}{ }^{+} \mathrm{OH}^{-}$and $44 \%$ for $\mathrm{G}-\mathrm{NPr}_{3}{ }^{+} \mathrm{I}^{-}$. The intensity of $\mathrm{D} 2$ is shown to be similar, within a $\pm 1 \%$ range for all three samples.

Additionally, TEM measurements were performed to determine the morphology of the particles. The images reveal flakes with diameters of up to $400 \mathrm{~nm}$ and with up to 7 layers (see Figure 4) for all three graphene samples. Individual sheets of G-non, however, show additional accumulation, forming larger "fluffy" aggregates.

Graphene Oxides. Graphene oxides show a broader variety of INA than graphene (see Figure 2). The $n_{\mathrm{s}}$ values of the (a)

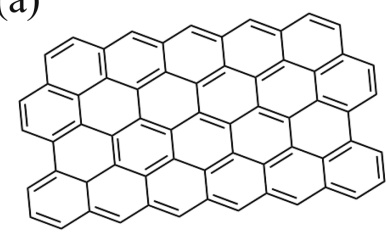

Non-functionalized graphene (G-non)

(c)

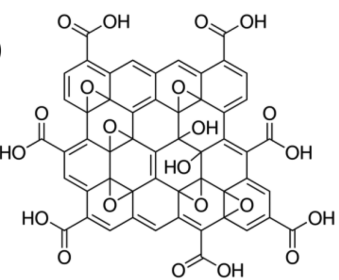

Graphene oxide nano-colloids (GO-nano) (b)

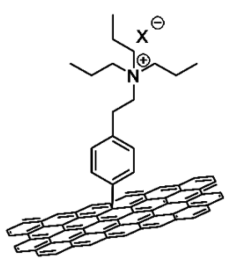

Covalently functionalized graphene $\left(\mathrm{G}-\mathrm{NPr}_{3}{ }^{+} \mathrm{X}, \mathrm{X}=\mathrm{I}\right.$ and $\left.\mathrm{OH}\right)$ (d)

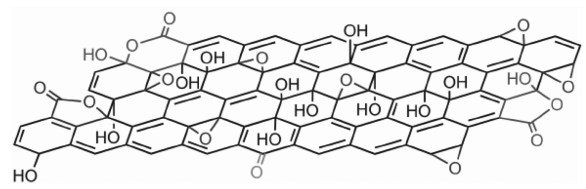

Graphene oxide (GO-DE, GO-SA)

(e)

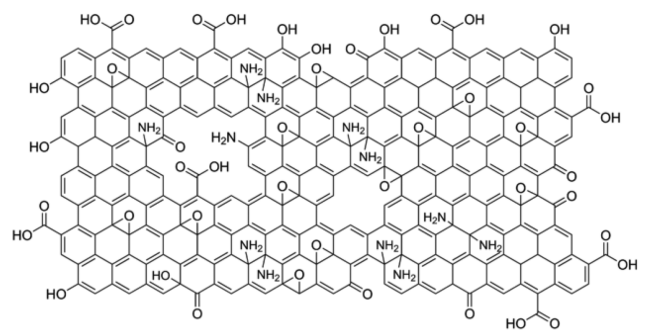

Ammonia-functionalized graphene $\left(\mathrm{GO}-\mathrm{NH}_{2}\right)$

Figure 1. Representative chemical structures of the samples investigated: (a) nonfunctionalized graphene G-non, ${ }^{44}$ (b) covalently functionalized graphene G-NPr ${ }_{3}^{+} \mathrm{X}^{-}(\mathrm{X}=\mathrm{I}$ and $\mathrm{OH})$, (c) graphene oxide nanocolloids GO-nano, (d) graphene oxide GO-DE and GO-SA, ${ }^{45}$ and (e) ammoniafunctionalized graphene oxide GO-ammo. According to the provided datasheet of the purchased material from Sigma-Aldrich Chemistry. 


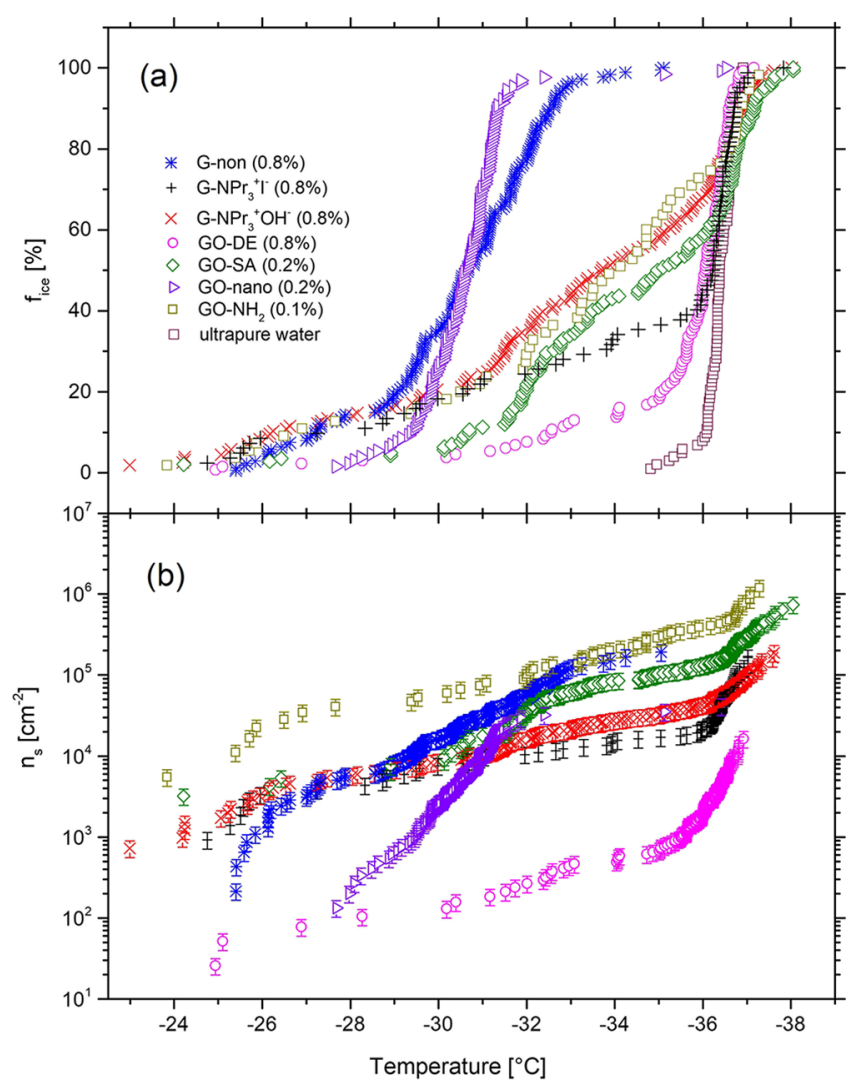

Figure 2. (a) Ratio of frozen droplets $f_{\text {ice }}$ and (b) the ice nucleation active surface site density $n_{\mathrm{s}}$ at a given temperature for all investigated samples. The $n_{\mathrm{s}}$ value, the freezing temperature range, and the $n_{\mathrm{s}}$ trend provide key information on the characteristics of the ice-nucleationactive samples of graphene or graphene oxides. Some droplets nucleate at about $-36{ }^{\circ} \mathrm{C}$, meaning that they do not contain INPs. Experimental uncertainty in the $n_{\mathrm{s}}$ value was calculated by changes in the weight and droplet size.

Table 3. Elemental Composition and $\mathbf{s p}^{2}$-Hybridized Carbon Proportion of All Investigated Graphene Samples Determined via XPS

\begin{tabular}{lccccc} 
& \multicolumn{4}{c}{ element [at. \%] } & \\
\cline { 2 - 5 } \multicolumn{1}{c}{ sample } & C & O & N & I & C-sp 2 [at. \%] \\
G-non & 91 & 9 & & & 86 \\
G-NPr $_{3}{ }^{+} \mathrm{I}^{-}$ & 92 & 4 & 3 & 1 & 91 \\
G-NPr $_{3}{ }^{+} \mathrm{OH}^{-}$ & 92 & 4 & 4 & & 72 \\
\hline
\end{tabular}

Table 4. Proportional Intensities of Fitted First-Order Raman Impulses (G, D1, and D2) According to Sadezky et al. $^{42}$ and Ratios of the Raman Band Intensity of the Disordered to the Ideal Graphitic Lattice (D/G) of All Investigated Graphene Samples

\begin{tabular}{llccc} 
& \multicolumn{4}{c}{ proportional intensity of fitted bands [\%] } \\
\cline { 2 - 5 } \multicolumn{1}{c}{ sample } & $\mathrm{G}$ & $\mathrm{D} 1$ & $\mathrm{D} 2$ & $\mathrm{D} / \mathrm{G}$ \\
G-non & 69 & 27 & 4 & 0.45 \\
$\mathrm{G}^{-\mathrm{NPr}_{3}} \mathrm{I}^{-}$ & 51 & 44 & 4 & 0.94 \\
$\mathrm{G}^{-} \mathrm{NPr}_{3}{ }^{+} \mathrm{OH}^{-}$ & 57 & 40 & 3 & 0.75 \\
\hline
\end{tabular}

chemically most similar graphene oxide samples GO-DE and GO-SA show a deviation of 2 orders of magnitude but an increase at a similar rate over the entire temperature window. The $n_{\mathrm{s}}$ value of GO-SA increases from $3 \times 10^{3} \mathrm{~cm}^{-2}$ at $-25^{\circ} \mathrm{C}$ to $10^{5} \mathrm{~cm}^{-2}$ at $-35{ }^{\circ} \mathrm{C}$ and that of GO-DE increases from 20 $\mathrm{cm}^{-2}$ at $-25{ }^{\circ} \mathrm{C}$ to $7 \times 10^{2} \mathrm{~cm}^{-2}$ at $-35^{\circ} \mathrm{C}$. GO-nano, on the other hand, initiates the ice nucleation process at a range similar to GO-DE at $-27.5^{\circ} \mathrm{C}$, with a $n_{\mathrm{s}}$ value of $130 \mathrm{~cm}^{-2}$. The $n_{\mathrm{s}}$ value, however, rises more steeply until it reaches the same value as GO-SA of $3 \times 10^{4} \mathrm{~cm}^{-2}$ at $-32.5{ }^{\circ} \mathrm{C}$. The functionalized graphene oxide sample $\left(\mathrm{GO}-\mathrm{NH}_{2}\right)$ shows the highest INA of all samples investigated over the entire freezing process, revealing $n_{\mathrm{s}}$ values between $10^{4} \mathrm{~cm}^{-2}$ at $-25^{\circ} \mathrm{C}$ and 3 $\times 10^{5} \mathrm{~cm}^{-2}$ at $-35^{\circ} \mathrm{C}$.

XPS measurements show a similar composition among all graphene oxide samples, that is, of approximately $67-73$ at. \% carbon and 23-33 at. \% oxygen (see Table 5). GO-nano is composed of an increased amount of oxygen (33 at. \%) and a consequently decreased proportion of carbon (67\%). GO-NH additionally consists of approximately 3 at. \% nitrogen due to the ammonia functionalization. The proportion of $\mathrm{sp}^{2}$ hybridized carbon lies between 19 at. \% for GO-nano and 45 at. \% for GO-DE.

Furthermore, Raman spectroscopy reveals distinctions in lattice orders (see Table 6 and Figure 5). In contrast to graphene, the graphene oxide samples show a more complex composition of lattice disorders. The $\mathrm{D} / \mathrm{G}$ ratio is a suitable indicator of the degree of disorder, which increases from GO$\mathrm{SA}$ (4.82) to $\mathrm{GO}-\mathrm{NH}_{2}$ (9.0). The $\mathrm{D}$ value summarizes the integral intensities of all D-bands (D1-D4): edge (D1) and surface (D2) disorders, amorphous graphene oxide features (D3), and ionic impurities/polyene disorders (D4). GO-DE exhibits an increased ratio of integrated intensities of D3 (7\%) and D4 (4\%) compared to the chemically most similar sample, GO-SA. The Raman spectrum of GO-nano reveals a disordered lattice with an integrated intensity of amorphous disorder of $11 \%$, making this sample the most amorphous of all samples. Nevertheless, GO- $\mathrm{NH}_{2}$ exhibits the more intense disorder, which is evident in the lowest integrated intensity of the ideal lattice of $10 \%$.

TEM analysis of GO-SA, GO-DE, and $\mathrm{GO}-\mathrm{NH}_{2}$ reveal similar large flakes of several $\mu \mathrm{m}$ in diameter and a thickness of 2-7 layers. GO-nano, on the other hand, consists of particles of varying shapes and sizes of up to $200 \mathrm{~nm}$ and thicknesses of at least $3 \mathrm{~nm}$ (see Figure 6).

\section{DISCUSSION}

Graphene. In Figure 2, the functionalized graphene samples show a similar INA, with slightly increased $n_{\mathrm{s}}$ values for G$\mathrm{NPr}_{3}{ }^{+} \mathrm{OH}^{-}$between -30 and $-36.5{ }^{\circ} \mathrm{C}$. In contrast, nonfunctionalized graphene (G-non) shows an increased INA above $-28{ }^{\circ} \mathrm{C}$ compared to the functionalized samples. TEM analyses indicate that the flake and layer size of functionalized graphene stay nearly the same as that of nonfunctionalized graphene. Differences in composition revealed by XPS might influence the INA because of the introduction of additional functional sites that are able to interact with water molecules and trigger ice formation. This would be consistent with the classical chemical-bonding requirement stated by Pruppacher and Klett. ${ }^{3}$ The Raman data revealed that covalently functionalized graphene $\left(\mathrm{G}-\mathrm{NPr}_{3}{ }^{+} \mathrm{I}^{-}\right.$and $\left.\mathrm{G}-\mathrm{NPr}_{3}{ }^{+} \mathrm{OH}^{-}\right)$exhibits an increased integrated intensity of lattice disorders. With a decrease in the $\mathrm{D} / \mathrm{G}$ ratio of functionalized graphene, the INA decreases at a similar rate (see Table 4). The functionalization process seems to have a major influence on the INA. The ordering process of water molecules at the water-graphene interface supports heterogeneous ice nucleation and depends 

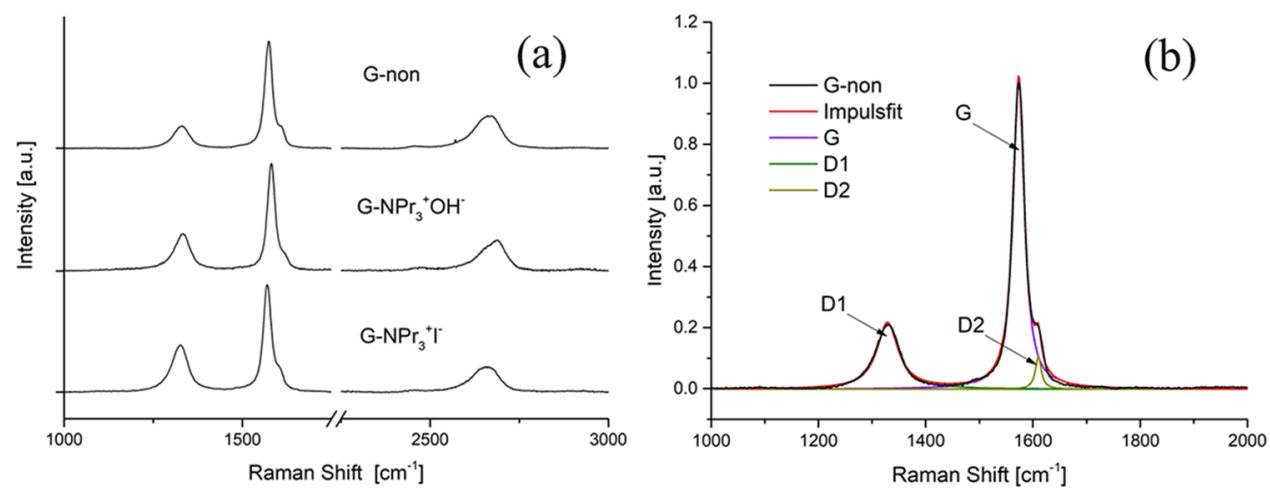

Figure 3. Raman spectra of (a) all investigated graphene samples and (b) nonfunctionalized graphene (G-non); first-order curve fitted with band combination according to Table $1\left(\lambda_{0}=633 \mathrm{~nm}\right)$.
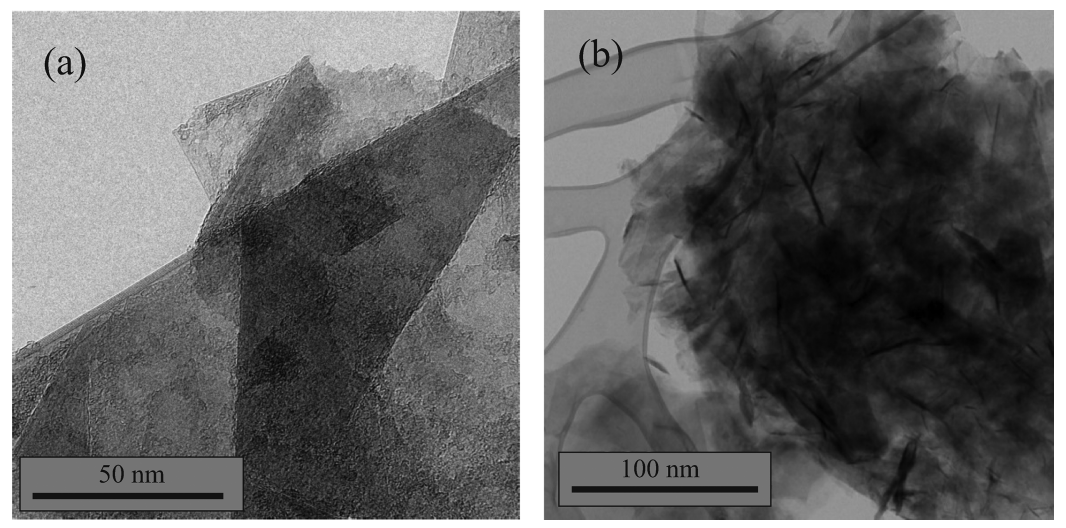

Figure 4. TEM images of graphene samples investigated: (a) nonfunctionalized graphene (G-non) indicates flakes with diameters of up to $400 \mathrm{~nm}$ and with up to 7 layers ${ }^{46}$ and (b) covalently functionalized graphene (G-NPr ${ }_{3}{ }^{-} \mathrm{I}^{-}$and G-NPr ${ }_{3}{ }^{+} \mathrm{OH}^{-}$) shows the same layer size and thickness as its nonfunctionalized precursor G-non but also shows individual sheets accumulating into larger "fluffy" aggregates.

Table 5. Elemental Composition and Proportion of $\mathbf{s p}^{2}$ Hybridized Carbon $\left(\mathrm{C}-\mathrm{Sp}^{2}\right)$ of All Investigated Graphene Oxide Samples Determined via XPS

\begin{tabular}{ccccc} 
& \multicolumn{3}{c}{ element [at. \%] } & \\
\cline { 2 - 4 } sample & $\mathrm{C}$ & $\mathrm{O}$ & $\mathrm{N}$ & C-sp ${ }^{2}$ [at. \%] \\
GO-SA & 71 & 28 & $<1$ & 29 \\
GO-DE & 72 & 27 & $<1$ & 45 \\
GO-nano & 67 & 33 & $<1$ & 19 \\
GO-NH & 73 & 23 & 3 & 42 \\
\hline
\end{tabular}

Table 6. Proportional Intensities of Fitted First-Order Raman Impulses (G, D1, and D2) According to Sadezky et al. $^{42}$ and Ratios of the Raman Band Intensity of the Disordered to the Ideal Graphitic Lattice (D/G) of All Investigated Graphene Oxide Samples

\begin{tabular}{|c|c|c|c|c|c|c|}
\hline \multirow[b]{2}{*}{ sample } & \multicolumn{6}{|c|}{ proportional intensity of fitted bands [\%] } \\
\hline & G & $\mathrm{D} 1$ & D2 & D3 & D4 & $\mathrm{D} / \mathrm{G}$ \\
\hline GO-SA & 17 & 68 & 7 & 5 & 2 & 4.82 \\
\hline GO-DE & 14 & 69 & 7 & 7 & 4 & 6.21 \\
\hline GO-nano & 14 & 64 & 6 & 11 & 5 & 6.14 \\
\hline GO-NH${ }_{2}$ & 10 & 70 & 8 & 8 & 4 & 9.0 \\
\hline
\end{tabular}

on the lattice features. Disorientations of the lattice disturb the interaction with liquid water and therefore lower the INA of graphene. Thus, the graphene lattice is a significant parameter influencing the INA of graphene and is also responsible for the INA of soot particles. This is consistent with calculations of
Lupi et al., ${ }^{26}$ Lupi and Molinero, ${ }^{21}$ and $\mathrm{Bi}$ et $\mathrm{al}^{22}$ and the laboratory work of Whale et al., ${ }^{25}$ which revealed that the ordering of liquid water on an ideal graphitic lattice plays an important role in the heterogeneous ice nucleation mechanism and any oxidation, roughness, or curvature was found to decrease the observed nucleation temperature. Nevertheless, accumulations of $\mathrm{G}-\mathrm{NPr}_{3}{ }^{+} \mathrm{I}^{-}$and $\mathrm{G}-\mathrm{NPr}_{3}{ }^{+} \mathrm{OH}^{-}$flakes into larger aggregates, as demonstrated in Figure 4, may reduce the INA by reducing the available active surface area, which needs to be considered. According to the data obtained in this study, it can be stated that the lattice conditions have an impact on the INA of graphene, yet the influence of agglomeration and functionalization cannot be excluded. However, more graphene species need to be investigated to state a significant trend and distinguish the relevance of each influence.

Graphene Oxides. The INA of graphene oxide appears to be more complex. In contrast to graphene, the graphene oxide samples not only show significant differences in composition but also experience additional lattice disorder. Because of oxidation, the $\mathrm{C}-\mathrm{sp}^{2}$ proportions of the graphene oxides were cut by one-half compared to the graphene samples because of an increased amount of carbon-containing contaminants (see Tables 3 and 5). The $n_{s}$ values of the chemically most similar graphene oxide samples, GO-DE and GO-SA, show a deviation of 2 orders of magnitude but increase at a similar rate over the entire temperature window. Furthermore, a consistent chemical composition and particle form was shown for both samples. In contrast, the lattice of GO-DE features an increased portion of structural disorder (D/G of 6.21) compared to GO-SA (D/G 

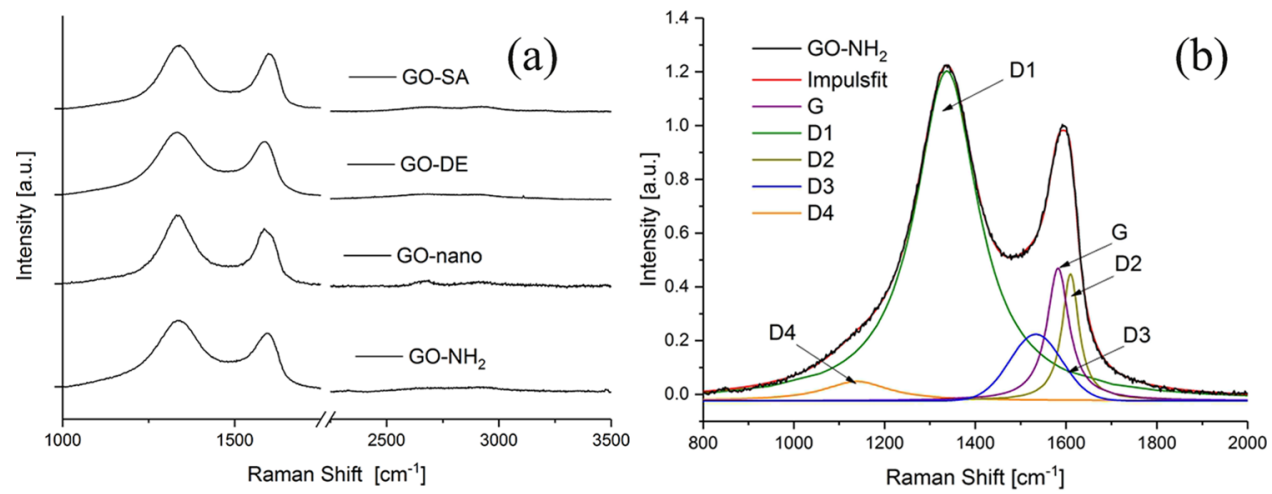

Figure 5. Raman spectra of (a) all investigated graphene oxide samples and (b) $\mathrm{GO}-\mathrm{NH}_{2}$; first-order curve fitted with band combination according to Table $1\left(\lambda_{0}=633 \mathrm{~nm}\right)$.
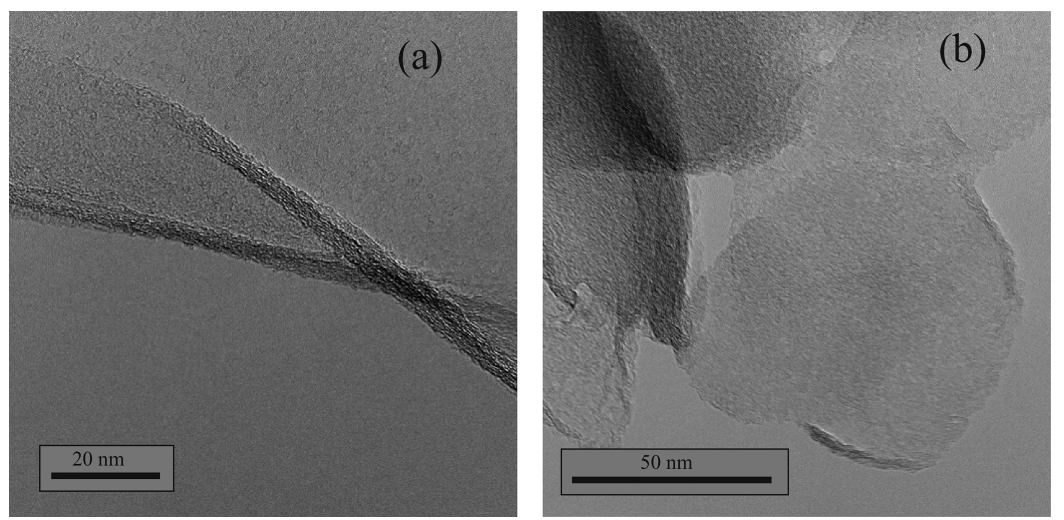

Figure 6. TEM images of the samples investigated: (a) nonfunctionalized (GO-SA and GO-DE) and ammonia-functionalized graphene oxides (GO$\mathrm{NH}_{2}$ ) reveal large flakes of approximately $5 \mathrm{~nm}$ thickness and several micrometers in diameter, and the thickness of the sheets and number of signals in the corresponding electron diffraction pattern indicate multi-layer graphene composed of 2-7 layers, while (b) GO-nano consists of particles of varying shapes with sizes of up to $200 \mathrm{~nm}$ and thickness of at least $3 \mathrm{~nm}$.

of 4.82). Because of the similarity in composition and particle shape, the significant differences in lattice order of GO-DE and GO-SA may account for the activity difference observed for the graphene samples. However, the observed dependence of INA on the lattice order cannot be applied to all graphene oxide samples investigated. In particular, GO-nano initiates ice nucleation in the same range as GO-DE, but nucleation increases substantially more steeply until it reaches the same value as GO-SA at $-32.5{ }^{\circ} \mathrm{C}$ (see Figure 2). The degree of graphitization, however, is in the same range as that of GO-DE and GO-SA, with an amorphous proportion of $11 \%$ being the highest of all samples (see Table 6). GO-nano shows an increased amount of oxygen (33 at. \%) and a corresponding decreased proportion of carbon (see Table 5). Nevertheless, GO-nano consists of significantly smaller particles of varying shapes and sizes of up to $200 \mathrm{~nm}$ and thicknesses of at least 3 $\mathrm{nm}$ (see Figure 6). On the basis of the data, three features may account for the increased INA of GO-nano: (i) the particle shape of GO-nano may cause an increase in the INA because of the beneficial arrangement of functional sites on the surface, (ii) additional oxygen groups act as functional sites and improve the interaction of the graphene oxide interface with water molecules because of a possible increase in hydrogen bonds, and (iii) the increased proportion of oxygen increases the hydrophilicity of graphene, reduces agglomeration, and hence increases the surface area. However, the influence of hydrophilicity and the resulting agglomeration is not clear. Biggs et al. $^{27}$ reported an increase in the INA due to a decrease in hydrophilicity. The resulting agglomeration may have led to a favorable positioning of the functional site and therefore to an increase in the INA, even though a decrease in the surface area occurs.

XPS measurements of GO- $\mathrm{NH}_{2}$ revealed a composition of 73 at. $\%$ carbon, 23 at. $\%$ oxygen, and 3 at. \% nitrogen due to functionalization. GO- $\mathrm{NH}_{2}$ exhibits the highest integrated intensity of disorder $(\mathrm{G}<10 \%)$ and the highest INA of all samples investigated. Amines are known to be more hydrophilic than comparable organic hydrocarbons because of their polarity and basicity. ${ }^{47}$ They therefore interact more easily with other polar groups, such as water molecules, via hydrogen bonds and may act as functional sites, increasing the INA. However, very few proteins show INA, despite containing lysine, an aminogroup-containing amino acid, and instead are known to act as antifreeze. ${ }^{48,49}$ The influence of increased hydrophilicity and therefore reduced agglomeration of $\mathrm{G}-\mathrm{NH}_{2}$ flakes in aqueous suspension may lead to an increased INA and cannot be excluded. Exfoliation can lead to an increase in the surface area and hence may increase the INA.

\section{SUMMARY}

In this work, we investigated the INA of different types of graphene and graphene oxides. Immersion drop freezing experiments as well as additional analytical analyses such as X-ray photoelectron spectroscopy, Raman spectroscopy, and transmission electron microscopy were performed to gain insight into the surface chemistry, micromorphology, and 
nanomorphology of the INPs. The investigation of graphene and graphene oxides show that the lattice order can have a major impact on the INA. The introduction of different kinds of disorders (layer edges, amorphousness, impurities, etc.) can influence the ability to perform heterogeneous ice nucleation. The ordering of water molecules at the interface to perform heterogeneous ice nucleation seems to depend on the graphitic lattice. Disorders in the lattice disturb the interactions with liquid water and therefore lower the INA of graphene. However, the observed dependence of the INA on the lattice order cannot be applied to all investigated graphene oxide samples. In particular, GO- $\mathrm{NH}_{2}$ exhibits the highest proportion of disorder $(\mathrm{G}<10 \%)$ and revealed the highest INA of all samples investigated. Functionalization with amines influences the INA by increasing the number of functional sites and/or by increasing the hydrophilicity. In general, two other INP characteristics in addition to the lattice order were shown to influence the INA of graphene and graphene oxides: (i) the particle size, in particular that within the nanometer range, may cause an increase in the INA due to the beneficial arrangement of functional sites on the surface and (ii) the degree of oxidation, which influences the hydrophilicity, reduces agglomeration, and hence increases the surface area, as well as generates functional sites.

On the basis of this work, the impact of the lattice order was demonstrated. Additionally, differences in structure, size, and functionalization between the investigated samples are shown. More species with closely controlled differences need to be investigated to state a firm experimental conclusion about the effect of each feature on the INA. Therefore, declarations of the most decisive ice nucleation feature cannot be made. A variety of features relevant to ice nucleation were shown to be essential when describing the ice-nucleating behavior of graphene and graphene oxides.

\section{ASSOCIATED CONTENT}

\section{S Supporting Information}

The Supporting Information is available free of charge on the ACS Publications website at DOI: 10.1021/acs.jpcc.7b10675.

Synthesis and characterization of functionalized graphene samples $\left(\mathrm{G}-\mathrm{NPr}_{3}{ }^{+} \mathrm{X}^{-}\right.$); visual comparison of graphene and graphene oxide suspensions after sonication and after settling for $30 \mathrm{~min}$; refreezing experiments of Gnon; and XPS-determined C 1s components of all samples (PDF)

\section{AUTHOR INFORMATION}

\section{Corresponding Author}

*E-mail: grothe@tuwien.ac.at. Phone: +43 (1) 58801165122. ORCID ${ }^{\circ}$

Thomas Häusler: 0000-0001-6375-0886

Daniel Iglesias: 0000-0002-1998-0518

Silvia Marchesan: 0000-0001-6089-3873

Dominik Eder: 0000-0002-5395-564X

Hinrich Grothe: 0000-0002-2715-1429

\section{Notes}

The authors declare no competing financial interest.

\section{ACKNOWLEDGMENTS}

We thank the Austrian Science Fund (FWF) for the financial support (project number P26040). XPS measurements were carried out using facilities of the "Analytical Instrumentation Center”, TU Wien, Austria. TEM measurements were performed at the University Service Centre for Transmission Electron Microscopy (USTEM, TU Wien).

\section{REFERENCES}

(1) Koop, T.; Luo, B.; Tsias, A.; Peter, T. Water Activity as the Determinant for Homogeneous Ice Nucleation in Aqueous Solutions. Nature 2000, 406, 611-614.

(2) Möhler, O.; Stetzer, O.; Schaefers, S.; Linke, C.; Schnaiter, M.; Tiede, R.; Saathoff, H.; Krämer, M.; Mangold, A.; Budz, P.; et al. Experimental Investigation of Homogeneous Freezing of Sulphuric Acid Particles in the Aerosol Chamber Aida. Atmos. Chem. Phys. 2003, 3, 211-223.

(3) Pruppacher, H. R.; Klett, J. D. Microphysics of Clouds and Precipitation; Kluwer Academic Publishers: Dordrecht, 1997.

(4) Szyrmer, W.; Zawadzki, I. Biogenic and Anthropogenic Sources of Ice-Forming Nuclei: A Review. B. Bull. Am. Meteorol. Soc. 1997, 78, 209-228.

(5) Murray, B. J.; O'Sullivan, D.; Atkinson, J. D.; Webb, M. E. Ice Nucleation by Particles Immersed in Supercooled Cloud Droplets. Chem. Soc. Rev. 2012, 41, 6519-6554.

(6) Lin, R.-F.; Starr, D. O.; DeMott, P. J.; Cotton, R.; Sassen, K.; Jensen, E.; Kärcher, B.; Liu, X. Cirrus Parcel Model Comparison Project. Phase 1: The Critical Components to Simulate Cirrus Initiation Explicitly. J. Atmos. Sci. 2002, 59, 2305-2329.

(7) Chang, S. G.; Novakov, T. Formation of Pollution Particulate Nitrogen-Compounds by No-Soot and Nh3-Soot Gas-Particle SurfaceReactions. Atmos. Environ. 1975, 9, 495-504.

(8) Novakov, T.; Chang, S. G.; Harker, A. B. Sulfates as Pollution Particulates: Catalytic Formation on Carbon (Soot) Particles. Science 1974, 186, 259-261.

(9) Rosen, H.; Hansen, A. D. A.; Dod, R. L.; Novakov, T. Soot in Urban Atmospheres: Determination by an Optical-Absorption Technique. Science 1980, 208, 741-744.

(10) DeMott, P. J. An Exploratory-Study of Ice Nucleation by Soot Aerosols. J. Appl. Meteorol. 1990, 29, 1072-1079.

(11) Dymarska, M.; Murray, B. J.; Sun, L.; Eastwood, M. L.; Knopf, D. A.; Bertram, A. K. Deposition Ice Nucleation on Soot at Temperatures Relevant for the Lower Troposphere. J. Geophys. Res.: Atmos. 2006, 111, D04204.

(12) Friedman, B.; Kulkarni, G.; Beránek, J.; Zelenyuk, A.; Thornton, J. A.; Cziczo, D. J. Ice Nucleation and Droplet Formation by Bare and Coated Soot Particles. J. Geophys. Res.: Atmos. 2011, 116, D17203.

(13) Kärcher, B.; Möhler, O.; DeMott, P. J.; Pechtl, S.; Yu, F. Insights into the Role of Soot Aerosols in Cirrus Cloud Formation. Atmos. Chem. Phys. 2007, 7, 4203-4227.

(14) Knopf, D. A.; Wang, B.; Laskin, A.; Moffet, R. C.; Gilles, M. K. Heterogeneous Nucleation of Ice on Anthropogenic Organic Particles Collected in Mexico City. Geophys. Res. Lett. 2010, 37, L11803.

(15) Pratt, K. A.; Heymsfield, A. J.; Twohy, C. H.; Murphy, S. M.; DeMott, P. J.; Hudson, J. G.; Subramanian, R.; Wang, Z. E.; Seinfeld, J. H.; Prather, K. A. In Situ Chemical Characterization of Aged BiomassBurning Aerosols Impacting Cold Wave Clouds. J. Atmos. Sci. 2010, 67, 2451-2468.

(16) Zuberi, B.; Johnson, K. S.; Aleks, G. K.; Molina, L. T.; Molina, M. J.; Laskin, A. Hydrophilic Properties of Aged Soot. Geophys. Res. Lett. 2005, 32, L01807.

(17) Cooper, D. R.; D’Anjou, B.; Ghattamaneni, N.; Harack, B.; Hilke, M.; Horth, A.; Majlis, N.; Massicotte, M.; Vandsburger, L.; Whiteway, E.; et al. Experimental Review of Graphene. ISRN Condens. Matter Phys. 2012, 2012, 1-56.

(18) Richter, H.; Howard, J. B. Formation of Polycyclic Aromatic Hydrocarbons and Their Growth to Soot-a Review of Chemical Reaction Pathways. Prog. Energy Combust. Sci. 2000, 26, 565-608.

(19) Böhm, H. P.; Clauss, A.; Fischer, G. O.; Hofmann, U. Das Adsorptionsverhalten Sehr Dünner Kohlenstoff-Folien. Z. Anorg. Allg. Chem. 1962, 316, 119-127. 
(20) Boehm, H.-P. Graphene-How a Laboratory Curiosity Suddenly Became Extremely Interesting. Angew. Chem., Int. Ed. 2010, 49, 93329335.

(21) Lupi, L.; Molinero, V. Does Hydrophilicity of Carbon Particles Improve Their Ice Nucleation Ability? J. Phys. Chem. A 2014, 118, $7330-7337$.

(22) Bi, Y.; Cabriolu, R.; Li, T. Heterogeneous Ice Nucleation Controlled by the Coupling of Surface Crystallinity and Surface Hydrophilicity. J. Phys. Chem. C 2016, 120, 1507-1514.

(23) Zheng, Y.; Su, C.; Lu, J.; Loh, K. P. Room-Temperature Ice Growth on Graphite Seeded by Nano-Graphene Oxide. Angew. Chem., Int. Ed. 2013, 52, 8708-8712.

(24) Steiner, T. The Hydrogen Bond in the Solid State. Angew. Chem., Int. Ed. 2002, 41, 48-76.

(25) Whale, T. F.; Rosillo-Lopez, M.; Murray, B. J.; Salzmann, C. G. Ice Nucleation Properties of Oxidized Carbon Nanomaterials. J. Phys. Chem. Lett. 2015, 6, 3012-3016.

(26) Lupi, L.; Hudait, A.; Molinero, V. Heterogeneous Nucleation of Ice on Carbon Surfaces. J. Am. Chem. Soc. 2014, 136, 3156-3164.

(27) Biggs, C. I.; Packer, C.; Hindmarsh, S.; Walker, M.; Wilson, N. R.; Rourke, J. P.; Gibson, M. I. Impact of Sequential SurfaceModification of Graphene Oxide on Ice Nucleation. Phys. Chem. Chem. Phys. 2017, 19, 21929-21932.

(28) Behera, S. N.; Sharma, M. Investigating the Potential Role of Ammonia in Ion Chemistry of Fine Particulate Matter Formation for an Urban Environment. Sci. Total Environ. 2010, 408, 3569-3575.

(29) Pandolfi, M.; Amato, F.; Reche, C.; Alastuey, A.; Otjes, R. P.; Blom, M. J.; Querol, X. Summer Ammonia Measurements in a Densely Populated Mediterranean City. Atmos. Chem. Phys. 2012, 12, $7557-7575$.

(30) Phan, N.-T.; Kim, K.-H.; Shon, Z.-H.; Jeon, E.-C.; Jung, K.; Kim, N.-J. Analysis of Ammonia Variation in the Urban Atmosphere. Atmos. Environ. 2013, 65, 177-185.

(31) Hauptmann, A.; Handle, K. F.; Baloh, P.; Grothe, H.; Loerting, T. Does the Emulsification Procedure Influence Freezing and Thawing of Aqueous Droplets? J. Chem. Phys. 2016, 145, 211923.

(32) Pummer, B. G.; Bauer, H.; Bernardi, J.; Bleicher, S.; Grothe, H. Suspendable Macromolecules Are Responsible for Ice Nucleation Activity of Birch and Conifer Pollen. Atmos. Chem. Phys. 2012, 12, 2541-2550.

(33) Zolles, T.; Burkart, J.; Häusler, T.; Pummer, B.; Hitzenberger, R.; Grothe, H. Identification of Ice Nucleation Active Sites on Feldspar Dust Particles. J. Phys. Chem. A 2015, 119, 2692-2700.

(34) Johnson, D. W.; Dobson, B. P.; Coleman, K. S. A Manufacturing Perspective on Graphene Dispersions. Curr. Opin. Colloid Interface Sci. 2015, 20, 367-382.

(35) Konios, D.; Stylianakis, M. M.; Stratakis, E.; Kymakis, E. Dispersion Behaviour of Graphene Oxide and Reduced Graphene Oxide. J. Colloid Interface Sci. 2014, 430, 108-112.

(36) Broadley, S. L.; Murray, B. J.; Herbert, R. J.; Atkinson, J. D.; Dobbie, S.; Malkin, T. L.; Condliffe, E.; Neve, L. Immersion Mode Heterogeneous Ice Nucleation by an Illite Rich Powder Representative of Atmospheric Mineral Dust. Atmos. Chem. Phys. 2012, 12, 287-307.

(37) Connolly, P. J.; Möhler, O.; Field, P. R.; Saathoff, H.; Burgess, R.; Choularton, T.; Gallagher, M. Studies of Heterogeneous Freezing by Three Different Desert Dust Samples. Atmos. Chem. Phys. 2009, 9, 2805-2824.

(38) DeMott, P. J. Quantitative Descriptions of Ice Formation Mechanisms of Silver Iodide-Type Aerosols. Atmos. Res. 1995, 38, 6399.

(39) Niedermeier, D.; Hartmann, S.; Shaw, R. A.; Covert, D.; Mentel, T. F.; Schneider, J.; Poulain, L.; Reitz, P.; Spindler, C.; Clauss, T.; et al. Heterogeneous Freezing of Droplets with Immersed Mineral Dust Particles-Measurements and Parameterization. Atmos. Chem. Phys. 2010, 10, 3601-3614.

(40) Edwards, G. R.; Evans, L. F.; La Mer, V. K. Ice Nucleation by Monodisperse Silver Iodide Particles. J. Colloid Sci. 1962, 17, 749-758.

(41) Whale, T. F.; Murray, B. J.; O'Sullivan, D.; Wilson, T. W.; Umo, N. S.; Baustian, K. J.; Atkinson, J. D.; Workneh, D. A.; Morris, G. J. A
Technique for Quantifying Heterogeneous Ice Nucleation in Microlitre Supercooled Water Droplets. Atmos. Meas. Tech. 2015, 8, 24372447.

(42) Sadezky, A.; Muckenhuber, H.; Grothe, H.; Niessner, R.; Pöschl, U. Raman Micro Spectroscopy of Soot and Related Carbonaceous Materials: Spectral Analysis and Structural Information. Carbon 2005, 43, 1731-1742.

(43) Weast, C. R.; Astle, M. J. Crc Handbook of Chemistry; CRC Press: Boca Raton, FL, 1981.

(44) Chakrabarti, M. H.; Low, C. T. J.; Brandon, N. P.; Yufit, V.; Hashim, M. A.; Irfan, M. F.; Akhtar, J.; Ruiz-Trejo, E.; Hussain, M. A. Progress in the Electrochemical Modification of Graphene-Based Materials and Their Applications. Electrochim. Acta 2013, 107, 425440.

(45) Gao, W.; Alemany, L. B.; Ci, L.; Ajayan, P. M. New Insights into the Structure and Reduction of Graphite Oxide. Nat. Chem. 2009, 1 403-408.

(46) Shearer, C. J.; Slattery, A. D.; Stapleton, A. J.; Shapter, J. G.; Gibson, C. T. Accurate Thickness Measurement of Graphene. Nanotechnology 2016, 27, 125704.

(47) Schirmeister, T.; Schmuck, C.; Wich, P. R.; Beyer, H.; Walter, W.; Francke, W. Organische Chemie; Hirzel Verlag: Stuttgart, 2016.

(48) Watanabe, M.; Makino, T.; Okada, K.; Kara, M.; Watabe, S.; Arai, S. Alkylbenzyldimethylammonium Salts as Inhibitors for the Ice Nucleating Activity of Erwinia-Ananas. Agric. Biol. Chem. 1988, 52, 201-206.

(49) Zachariassen, K. E.; Kristiansen, E. Ice Nucleation and Antinucleation in Nature. Cryobiology 2000, 41, 257-279. 